\title{
Buckyballs (fullerenes): free radical sponges or inflammatory agents?
}

\author{
C. Cadenas $\cdot$ R. Marchan $\cdot$ J. G. Hengstler
}

Published online: 6 November 2012

(c) Springer-Verlag Berlin Heidelberg 2012

In this issue, Andreja Trpkovic, Biljana TodorovicMarkovic and Vladimir Trajkovic from Belgrade contribute a comprehensive review on the in vitro and in vivo toxicity of fullerenes, also named "Buckyballs" (Trpkovic et al. 2012; this issue). "Buckyballs" are molecules composed entirely of carbon, named after Richard Buckminster Fuller. Particularly, well known is the $\mathrm{C}_{60}$ fullerene, which resembles a nanoscale football. Fullerenes can also form cylindrical structures, aptly named buckytubes or nanotubes. The existence of $\mathrm{C}_{60}$ was predicted already in the 1970s by scientists from both the USSR and Japan (Henson and Osawa) based on quantum-chemical considerations. However, this discovery was initially not acknowledged in Europe and America. Later, Kroto, Curl and Smallery, incidentally from the USA and the UK, were awarded the Nobel Prize in 1996 for the discovery of $\mathrm{C}_{60}$ fullerenes.

Today, fullerenes are invaluable to the field of nanotechnology, because of their superconductivity and heat resistance. Moreover, they are studied for their potential medical use as drug delivery systems. However, air fullerenes are also environmental contaminants, most probably as a result of combustion processes, for example, in coal power plants. Buckyballs have also been detected in outer space and discussed as "seeds for life" on earth, although this is all speculative.

Because of their chemical and toxicological properties, it seems to be relevant that fullerenes are not completely

C. Cadenas $(\bowtie) \cdot$ R. Marchan · J. G. Hengstler Leibniz Institut für Arbeitsforschung an der TU Dortmund, Leibniz Research Centre for Working Environment and Human Factors (IfADo), Ardeystrasse 67, 44139 Dortmund, Germany

e-mail: cadenas@ifado.de unreactive. To form a closed sphere, the $\mathrm{sp}^{2}$-hybridized carbon atoms must be bent, thus producing angle strain. The $\mathrm{C}_{60}$ fullerene contains thirty double bonds and readily binds free radicals. On the other hand, in vitro tests have shown the following effects upon exposure to fullerenes:

- generation of reactive oxygen species

- activation of signaling factors

- mitochondrial depolarization

- induction of autophagy, reflected by an increase in acidified vacuoles or levels of the autophagosome marker LC3-II

- lipid peroxidation

- lysis of erythrocytes

Although fullerenes accumulate in the lung, liver, spleen and kidney, in vivo toxicity seems to be minimal. Inflammatory reactions in the lung and liver, as well as increased neutrophil counts, have been reported. However, high doses are required to induce toxicity in vivo. Currently, adverse effects of nanomaterials represent a cutting-edge topic in toxicology (Kim et al. 2011a, b, 2012; Zhang et al. 2011; Ronzani et al. 2012; Nakagawa et al. 2011; Marchan 2011a, b, 2012; Hengstler 2011). The current review of Trajkovic and colleagues gives a systematic and complete overview of the toxicity studies both in vitro and in vivo performed with fullerenes.

\section{References}

Hengstler JG (2011) Cutting-edge topics in toxicology. EXCLI J 10:117-119

Kim JS, Lee K, Lee YH, Cho HS, Kim KH, Choi KH, Lee SH, Song KS, Kang CS, Yu IJ (2011a) Aspect ratio has no effect on genotoxicity of multi-wall carbon nanotubes. Arch Toxicol 85(7):775-786 
Kim JS, Song KS, Lee JH, Yu IJ (2011b) Evaluation of biocompatible dispersants for carbon nanotube toxicity tests. Arch Toxicol 85 (12):1499-1508

Kim JS, Song KS, Lee JK, Choi YC, Bang IS, Kang CS, Yu IJ (2012) Toxicogenomic comparison of multi-wall carbon nanotubes (MWCNTs) and asbestos. Arch Toxicol 86(4):553-562

Marchan R (2011a) Highlights in toxicology. EXCLI J 10:223-229

Marchan R (2011b) Oxidative stress research. EXCLI J 10:120-123

Marchan R (2012) A special issue on nanotoxicology. EXCLI J 11: 176-177

Nakagawa Y, Suzuki T, Ishii H, Nakae D, Ogata A (2011) Cytotoxic effects of hydroxylated fullerenes on isolated rat hepatocytes via mitochondrial dysfunction. Arch Toxicol 85(11):1429-1440
Ronzani C, Spiegelhalter C, Vonesch JL, Lebeau L, Pons F (2012) Lung deposition and toxicological responses evoked by multiwalled carbon nanotubes dispersed in a synthetic lung surfactant in the mouse. Arch Toxicol 86(1):137-149

Trpkovic A, Todorovic-Markovic B, Trajkovic V (2012) Toxicity of pristine versus functionalized fullerenes: mechanisms of cell damage and the role of oxidative stress. Arch Toxicol. doi: 10.1007/s00204-012-0859-6

Zhang M, Li J, Xing G, He R, Li W, Song Y, Guo H (2011) Variation in the internalization of differently sized nanoparticles induces different DNA-damaging effects on a macrophage cell line. Arch Toxicol 85(12):1575-1588 